\title{
História da radiofarmácia e as implicações da Emenda Constitucional N. 49
}

\author{
Ralph Santos-Oliveira*1, Ana Maria dos Anjos Carneiro-Leão \\ ${ }^{1}$ Comissão Nacional de Energia Nuclear, ${ }^{2}$ Universidade Federal Rural de Pernambuco
}

*Correspondência:

R. S. Oliveira

Comissão Nacional de Energia

Nuclear

Av. Prof. Luiz Freire, 200, CDU

50.740-540 - Recife - PE, Brasil

Email: roliveira@cnen.gov.br.

\author{
$O$ objetivo deste artigo é descrever a história dos radiofármacos \\ e as implicações da Emenda Constitucional N. 49 sobre a produção \\ de radiofármacos no Brasil.
}

\section{Unitermos}

- Radiofarmácia

- Radiofármacos/produção/ aspectos legislativos

- Emenda 49/implicações

\section{INTRODUÇÃO}

Historicamente, os radiofármacos começaram a ser utilizados em 1905, após a descoberta em 8 de novembro de 1895 do Raio-X por Wilhelm Conrad Roentgen em seu laboratório, com apresentação pública de sua descoberta em 6 de janeiro de 1896 (Early, Landa, 1995; Early, 1995;

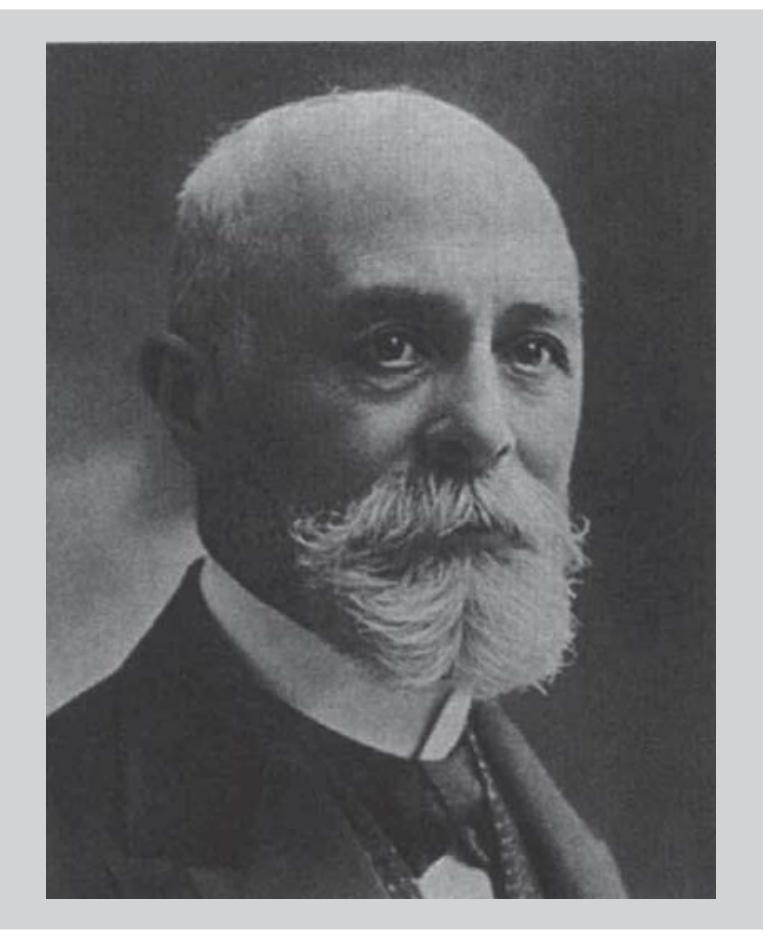

FIGURA 1 - Henri Becquerel. Fonte: Early, Landa (1995).
Landa, 1987). Neste cenário, diversos personagens importantes foram destaque, dentre eles Marie Sklodowska (mais tarde Marie Curie), Henri Becquerel e Pierre Curie (Early, Landa, 1995).

A evolução da medicina nuclear e conseqüentemente da radiofarmácia, foi marcada de grandes descobertas e grandes fracassos, além de engenhosos equipamentos e métodos (Simpson, 1922; Taussig, 1923; Saubermann, 1914) .

O primeiro uso de radionuclídeos em humanos ocorreu em 1927, quando Blumgart e Yens mediram a circulação humana após injeção de um solução salina exposta ao radônio (Blumgart, Yens, 1926). Mais tarde, em 1938, estudos como de Hertz, Roberts, Evan sobre a função da tiróide com o uso de iodo-121 marcaram o início do uso sistemático dos radionuclídeos na clínica médica (Hertz, Roberts, Evans, 1938).

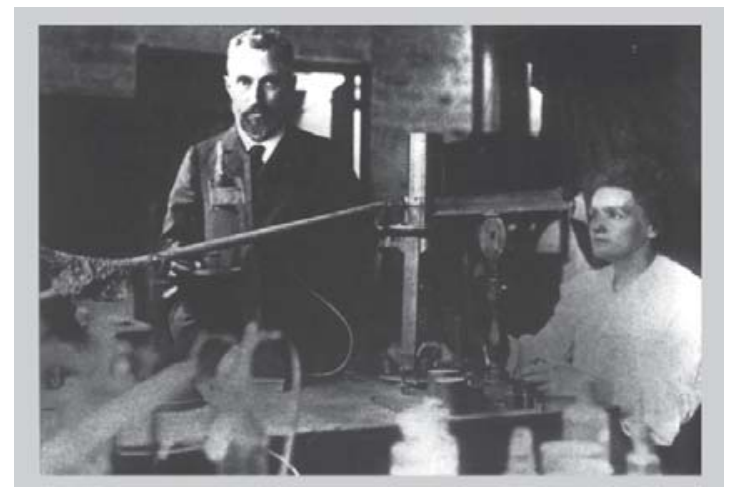

FIGURA 2 - Marie e Pierre Curie. Fonte Early, Landa (1995). 


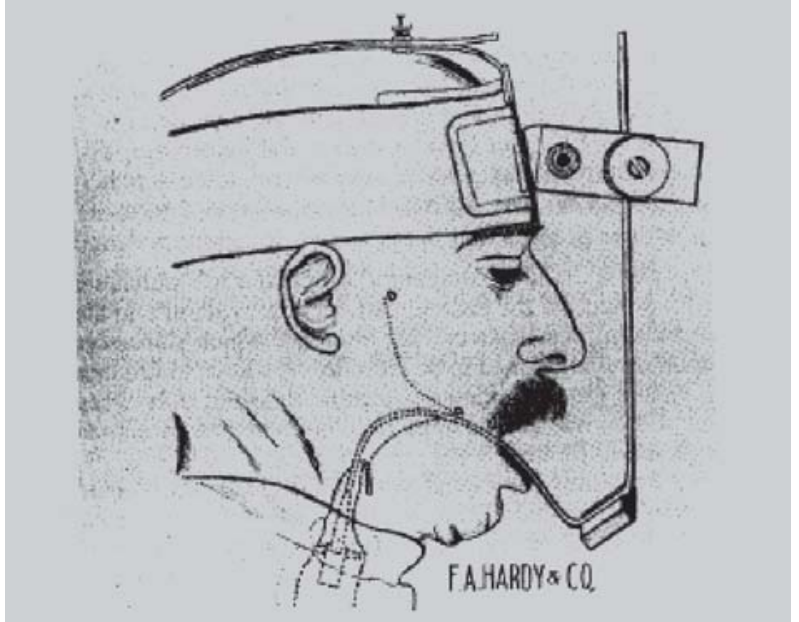

FIGURA 3 - Equipamento para tratamento de tumor de laringe. Fonte: Simpson, (1922).

Os radiofármacos tiveram duas divisões históricas bem marcantes, comumente denominadas de Fase I ou Fase Pré-Tecnécio e Fase II ou Fase Pós-Tecnécio. A Fase I foi marcada pela publicação na Revista Science, em 14 de junho de 1945, de um artigo do Oak Ridge National Laboratories anunciando a disponibilidade de radionuclídeos ao setor privado. Pouco tempo depois ao anúncio do Oak Ridge National Laboratories, o Brookhaven National Laboratories também disponibilizou ao setor privado os radionuclídeos por eles produzidos (Oak Ridge National Laboratories 1945). Nesta época, os radionuclídeos eram disponibilizados sem nenhuma garantia de esterilidade e apirogenicidade, sendo incluídos estes parâmetros somente mais tarde, quando a Abbot Laboratories decidiu comprar a produção de radionuclídeos desses laboratórios e transformá-los em radiofármacos (radionuclídeo devidamente preparado) para uso médico, tornando-se a primeira produtora de radiofármacos no mundo. Somente após cinco anos, outras empresas começaram a se interessar pelo setor, a $S q u i b b$ Co. e a Nuclear Consultants Corporation (Early, 1995). O primeiro radiofármaco comercialmente disponível foi o Iodo-131 e sua comercialização só começou em 1950.

Em relação à Fase II, esta foi deflagrada com a descoberta do tecnécio (Tc-99m), naquela época denominado Elemento Número 43. No início, o tecnécio não se mostrou um bom candidato para uso na medicina nuclear, pela meia-vida de 6 horas. Contudo, este possuía uma energia gama ideal para formação de imagens ( $140 \mathrm{keV})$ e este se enquadrou de forma perfeita no projeto de desenvolvimento de metodologia para a formação de radionuclídeos de meia-vida curta, liderado pelo Brookhaven National Laboratories. Em 1957, foi então anunciado o desenvolvimento do gerador de tecnécio, pelo sistema Mo-99/Tc-99m (Early, 1995).

No Brasil, os primeiros passos nesse sentido foram, dados a partir de 1956, quando pelo convênio entre o CNPq (Conselho Nacional de Pesquisa) e USP (Universidade de São Paulo) foi criado o IEA (Instituto de Energia Atômica) (Silva, 2002). Em 1959, começam os trabalhos pioneiros do IEA no campo dos radionuclídeos com a produção de

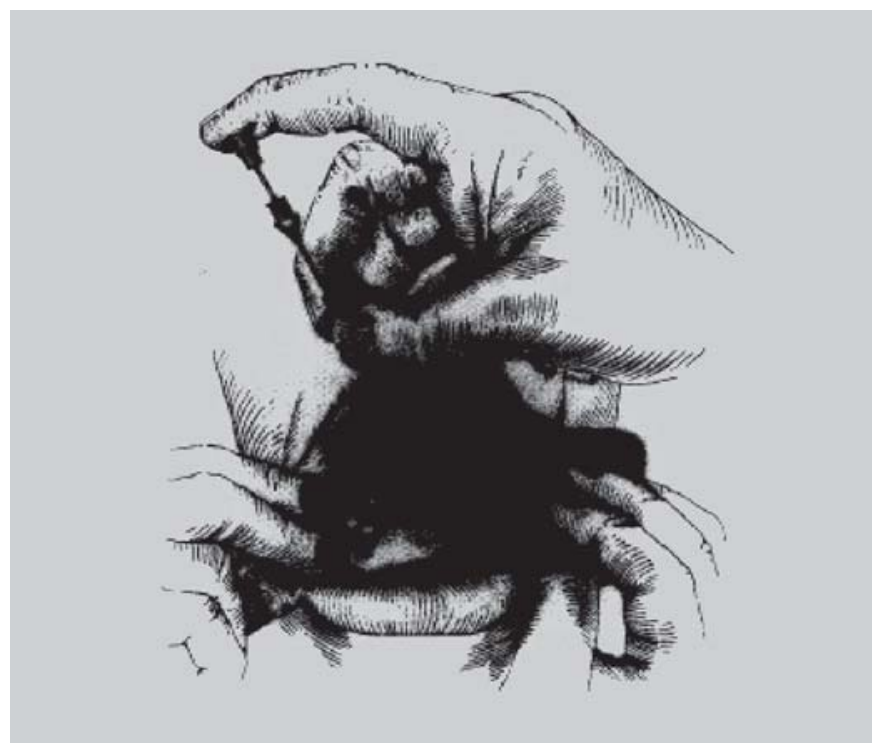

FIGURA 4 - Método de implantação de sementes de rádio na língua. Fonte: Taussig, 1923. "Observar a falta de equipamento de proteção do paciente e do médico que aplica".

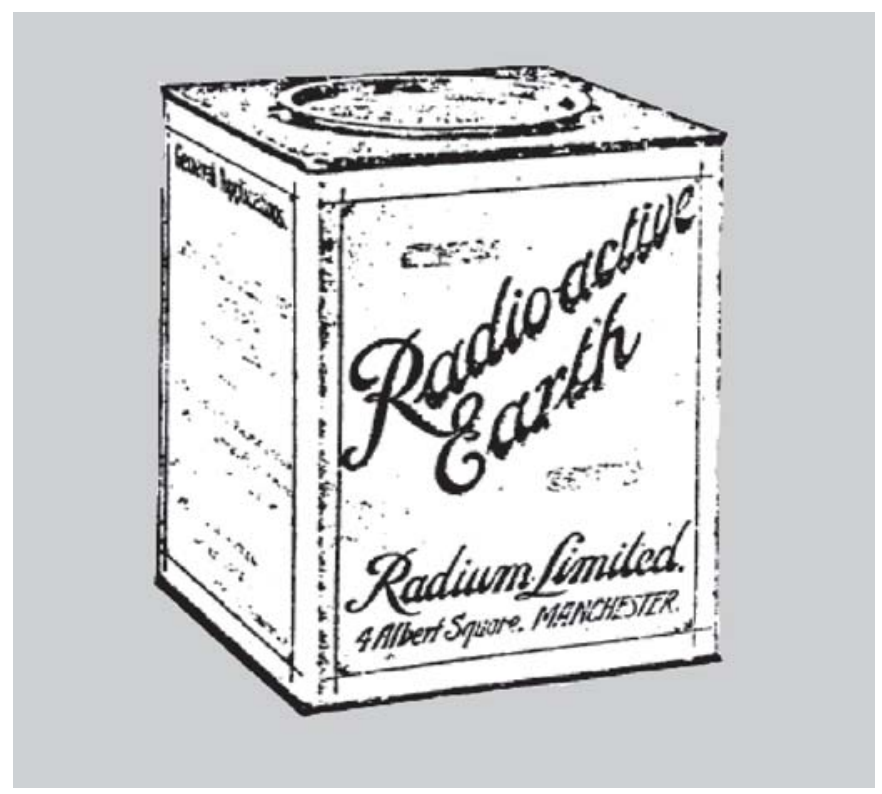

FIGURA 5 - Medicamento à base de produto radioativo vendido na época. Fonte: Saubermann, 1914. "Atentar para o desconhecimento dos feitos maléficos destas substâncias". 
Iodo-131 para aplicação médica. Somente quatro anos mais tarde, em 1963, o IEA, atualmente IPEN (Instituto de Pesquisas Energéticas e Nucleares), começou a produção rotineira de radioisótopos e depois com a inclusão dos procedimentos farmacêuticos de radiofármacos. Desde 1956 até 2006, o monopólio de produção de radioisótopos e radiofármacos sempre pertenceu à Comissão Nacional de Energia Nuclear, pela promulgação na Constituição do Brasil.

O desenvolvimento de uma nova ciência pode ser dividido em três fases: a) descoberta; b) os problemas relacionados à descoberta e c) o alcance da maturidade no novo campo descoberto (Wolf, Tubis, 1967). Os radiofármacos passaram por todas essas fases e encontramse hoje na terceira fase.

Os radiofármacos compreendem: os geradores de radionuclídeos, os conjuntos de reativos liofilizados para marcar com Tc-99m ou Kits e os precursores de radiofármacos. $\mathrm{O}$ gerador de radionuclídeos é um sistema de preparação de radiofármacos onde se utiliza um radionuclídeo de meia-vida longa que decai num outro radionuclídeo o qual é eluído (ou extraído por métodos de extração) para a preparação do radiofármaco. Os kits para a preparação de radiofármacos podem ser preparações liofilizadas para serem reconstituídas e/ou combinadas com radionuclídeos na preparação final de radiofármacos. Quanto aos precursores de radiofármacos, estes podem ser qualquer radionuclídeo produzido por radio-marcação de uma substância, antes da administração (The International Pharmacopoeia, 2004).

\section{EMENDA CONSTITUCIONAL N. 49}

A Emenda Constitucional n. 49, de 8 de fevereiro de 2006 (Brasil, 2006) excluiu do monopólio da União a produção, a comercialização e a utilização de radioisótopos de meia-vida curta, para usos médicos, agrícolas e industriais. A mais recente modificação da Constituição brasileira de 1988 se deu pela alteração da redação da alínea b, acréscimo de uma alínea c ao inciso XXIII do caput do artigo 21 e pela nova redação dada ao inciso $\mathrm{V}$ do caput do artigo 177.

Nascida da PEC (Proposta de Emenda Constitucional) 199/03, que retira da União o monopólio da produção, comercialização e da utilização de radioisótopos de meiavida curta, a EC n. 49 facilitou a criação de novos centros de medicina nuclear que ofereçam o serviço de tomografia à população. Os radioisótopos de meia-vida curta são produzidos por institutos da CNEN (Comissão Nacional de Energia Nuclear) como o IEN (Instituto de Engenharia Nuclear), o IPEN (Instituto de Pesquisas Energéticas e Nucleares) e futuramente no CRCN-NE (Centro Regional de Ciências Nucleares do Nordeste).

\section{IMPLICAÇÕES}

\section{Artigo 60, $3^{\circ}$ da Constituição Federal}

As mesas da Câmara dos Deputados e do Senado Federal, nos termos do artigo 60 da Constituição Federal, promulgam a seguinte Emenda ao texto constitucional. $\mathrm{O}$ Artigo 60 da Constituição da República prevê e disciplina como devem ser realizadas as emendas constitucionais. As emendas à Constituição são previstas no artigo 59 como parte do processo legislativo brasileiro.

As emendas constitucionais promulgadas no Brasil a partir de 1992 explicitavam todas elas que haviam sido promulgadas nos termos do artigo $60, \S 3^{\circ}$ da Constituição da República. Entretanto, a partir da Emenda Constitucional n. 48, de 10 de agosto de 2005, não foi mais feita referência ao parágrafo terceiro do referido artigo. O parágrafo em questão determina que a emenda à Constituição deva ser promulgada pelas mesas da Câmara dos Deputados e do Senado Federal, com o respectivo número de ordem (Mafra-Filho, 2006; Oliveira, Carneiro-Leão, 2007).

\section{Artigo1 ${ }^{\circ}$}

$\mathrm{O}$ artigo $1^{\circ}$ da EC N. 49 altera o inciso XXIII, do artigo 21 da Constituição Federal. $\mathrm{O}$ artigo 21 trata das competências da União. O caput do inciso XXIII determina que à União compete "explorar os serviços e instalações nucleares de qualquer natureza e exercer monopólio estatal sobre a pesquisa, a lavra, o enriquecimento e reprocessamento, a industrialização e o comércio de minérios nucleares e seus derivados, atendidos os princípios e condições" que se estabelecem nas alíneas a seguir.

A primeira alínea do inciso XXIII estabelece o princípio por meio do qual "toda atividade nuclear em território nacional somente será admitida para fins pacíficos e mediante aprovação do Congresso Nacional". A alínea $b$, modificada pela Emenda Constitucional n. 49, estabelecia que "sob regime de concessão ou permissão, era autorizada a utilização de radioisótopos para a pesquisa e usos medicinais, agrícolas, industriais e atividades análogas".

Deve ser notada a modificação da alínea $b$, do inciso XXIII, do artigo 21 da Constituição Federal pela EC n.49 que retirou a antiga previsão de que, por meio de concessão ou de permissão, era autorizada a utilização de radioisótopos para a pesquisa e usos medicinais, agrícolas, industriais e atividades análogas.

A partir da promulgação da Emenda n. 49, a alínea $b$ estabelece que apenas "sob regime de permissão, são autorizadas a comercialização e a utilização de radioisótopos para a pesquisa e usos médicos, agrícolas e industriais". A retirada da 
concessão tem seus significados relevantes. Em sede de direito administrativo, é de se notar que a concessão de um serviço público ou de algo de competência do Estado é o instrumento utilizado pelo Poder Público para que empresas públicas ou particulares realizem aquele serviço ou aquela prestação.

O mesmo acontece com a permissão. As diferenças que há, entretanto, entre concessões e permissões são relevantes. A concessão é realizada para empreendimentos maiores, mais duradouros e, principalmente, de valores econômicos e financeiros mais relevantes. As permissões são feitas para serviços não tão caros, não tão longos no tempo e, principalmente, podem ser desfeitas (Mafra-Filho, 2006; Oliveira, Carneiro-Leão, 2007).

\section{Artigo $2^{\circ}$}

$\mathrm{O}$ artigo $2^{\circ}$ da EC n. 49 altera a redação do inciso $\mathrm{V}$ do caput do artigo 177 da Constituição Federal. O artigo 177 estabelece os monopólios da União. O inciso $\mathrm{V}$ declarava que eram monopólios da União a pesquisa, a lavra, o enriquecimento, o reprocessamento, a industrialização e o comércio de minérios e minerais nucleares e seus derivados. Doravante, o inciso V determina que, dentro dos monopólios da União, “a pesquisa, a lavra, o enriquecimento, o reprocessamento, a industrialização e o comércio de minérios e minerais nucleares e seus derivados, são monopólios da União", com exceção agora dos radioisótopos de meiavida curta, cuja produção, comercialização e utilização poderão ser autorizadas sob regime de permissão, conforme as alíneas $b$ e $c$ do inciso XXIII do caput do artigo 21 da Constituição Federal", que passam a vigorar após a EC n. 49/06.

O que deve ser observado é que a alteração na competência da União gerou uma modificação no seu artigo que prevê o monopólio do governo federal sobre algumas atividades. Doravante, a produção, comercialização e utilização de radioisótopos poderão ser realizadas sob regime de permissão.

\section{Artigo $3^{\circ}$}

Segundo Mafra-Filho (2006), o último artigo da EC n. 49 estabelece a sua imediata produção de efeitos assim que for publicada. Isto quer dizer que a partir do dia 9 de fevereiro de 2006, data de sua publicação no Diário Oficial da União, as determinações da Emenda Constitucional n. 49 já estão em vigor no ordenamento jurídico brasileiro.

\section{CONCESSÕES E PERMISSÕES DE SERVIÇOS PÚBLICOS}

O significado da palavra permissão é amplo e pode expressar o significado de ato administrativo unilateral, sem a natureza contratual, discricionário e precário, gratuito ou oneroso, pelo qual a administração pública faculta ao particular a execução de serviço público ou a utilização privativa de bens públicos por terceiros. O objeto da permissão é a execução de serviço público ou a utilização privativa de bens públicos, chamados, respectivamente, permissão de serviço público e permissão de uso.

$\mathrm{O}$ artigo 175 da Constituição Federal reza que "incumbe ao poder público, na forma da lei, diretamente ou sob o regime de concessão ou permissão, sempre através de licitação, a exploração de serviços públicos”.

A principal forma de distinção de concessão e permissão é justamente a de que a concessão tem natureza contratual e a permissão é ato unilateral, discricionário e precário, sendo, portanto, despida de qualquer caráter contratual.

Mello (2001) define a permissão de serviço público como "o ato unilateral e precário", intuitu personae, através do qual o Poder Público transfere a alguém o desempenho de um serviço e sua alçada, proporcionando, à moda do que faz na concessão, a possibilidade de cobrança de tarifas dos usuários" e ainda "o Estado, em princípio, valer-seia da permissão justamente quando não desejasse constituir o particular em direitos contra ele, mas apenas em face de terceiros".

De acordo com Mafra-Filho (2006) "pelo seu caráter precário, caberia utilizá-la normalmente, quando o permissionário não necessitasse alocar grandes capitais para o desempenho do serviço ou quando poderia mobilizar, para diversa destinação e sem maiores transtornos, o equipamento utilizado ou, ainda, quando o serviço não envolvesse implantação física de aparelhamento que adere ao solo, ou, finalmente, quando os riscos da precariedade a serem assumidos pelo permissionário fossem compensáveis seja pela extrema rentabilidade do serviço, seja pelo curtíssimo prazo em que se realizaria a satisfação econômica almejada".

Continuando a distinção entre concessão e permissão, devem ser ressaltados os seguintes aspectos decorrentes da precariedade desta última. Precariedade significa que tanto o ato é revogável a qualquer tempo pela iniciativa da administração pública, quanto outorga sem estabelecimento de prazo e revogável, a qualquer tempo pela administração, sem direito a indenização. Vistas estas características iniciais da permissão, ainda há outras também presentes, como:

a) precariedade no ato e delegação;

b) natureza contratual adesiva (contrato de adesão);

c) revogabilidade unilateral pelo poder concedente;

d) possibilidade de a permissão ser feita a pessoa física, o que não está previsto para a concessão;

e) a possibilidade de que o serviço público seja prece- 
dido de obra pública está prevista somente para os casos de concessão haja vista a incompatibilidade do instituto da permissão para obras públicas.

Em se tratando de autorização de serviço público, a atual Constituição Federal, em seu artigo 175 vem incompleta ao referir-se tão somente a concessões e permissões. Entretanto, no artigo 21 inciso XII, encontram-se arrolados os serviços que a União pode executar diretamente ou mediante autorização, concessão ou permissão. Também na legislação ordinária, isto é, nas leis ordinárias, a autorização vem mencionada, ao lado da permissão e da concessão como forma de delegação de serviços públicos. É ela ato unilateral e discricionário pelo qual a administração pública faculta ao particular o desempenho de atividade material ou a prática de ato que necessite deste consentimento para ser legítimo, ou seja, trata-se da autorização como ato praticado no exercício do poder de polícia.

Em resumo, pode-se dizer que classicamente mediante a permissão e a autorização, também a Administração transfere a execução de serviços públicos a particulares. Proceder à distinção substancial entre concessão e permissão de serviço público, é uma tarefa difícil, posto que ambas implicam prestação de serviços públicos por particulares, por remuneração assegurada pela tarifa que os usuários pagam para a utilização do serviço. Tanto a permissão quanto a concessão admitem alto grau de exigência e complexidade. O critério da maior ou menor relevância do serviço não oferece, igualmente, critério diferenciador. No ordenamento jurídico brasileiro, um ponto de diferença entre concessão e permissão situa-se na possibilidade conferida aos concessionários de promover desapropriações, desde que existente prévia autorização expressa, constante de lei ou contrato. Tal possibilidade decorre do artigo $3^{\circ}$ do Decreto Lei 3.365, de 21/06/41 (Lei de Desapropriações por utilidade pública), não extensiva, ressalte-se, aos que ganham uma permissão de serviço público.

Ainda outros critérios diferenciadores extraídos do modo de expressão das duas figuras é que a concessão se dará por meio de contrato e a permissão por meio de ato administrativo, discricionário, precário e revogável, em princípio, a qualquer tempo. Entretanto, a Constituição Federal de 1988 ao exigir o procedimento da licitação para ambas as figuras, aproximou a permissão da forma contratual. Finalmente, a Lei $n^{\circ} 8.987 / 95$, em seu artigo 40 determinou que a sua formalização se dará através de contrato e adesão, observadas a precariedade e a revogabilidade unilateral do contrato pelo poder concedente.

Em respeito à autorização, podemos concluir que permanece a sua formalização através de ato administrativo precário e discricionário, recomendando-se a sua utili- zação para os serviços que apresentem menor complexidade, nem sempre remunerados por meio tarifário. Exemplificando-se temos o caso da autorização para conservação de praças, jardins ou canteiros de avenidas, em troca da afixação de placas com propaganda da empresa. Ainda, a autorização não é objeto de regulamentação legal pela Lei n ${ }^{\circ}$ 8.987/95 (Oliveira, Carneiro-Leão, 2007).

\section{RESPONSABILIDADE CIVIL OBJETIVA}

A anterior alínea $c$ previa que a responsabilidade civil por danos nucleares não era dependente da existência de culpa, ou seja, era objetiva. A partir da Emenda Constitucional n. 49, a alínea $c$ passou a determinar que, sob regime de permissão, são autorizadas a produção, comercialização e utilização de radioisótopos de meia-vida igual ou inferior a duas horas. A alínea $d$, incluída pela EC n. 49 , herdou a previsão de responsabilidade civil objetiva por danos nucleares, ou seja, a responsabilidade civil independente da existência de culpa.

A competência da União para explorar os serviços e as instalações nucleares de qualquer natureza e exercer o monopólio estatal sobre pesquisa, lavra, enriquecimento, a industrialização e o comércio de minérios nucleares e seus derivados decorre da importância e do perigo que representam os assuntos relacionados à energia nuclear. O primeiro princípio que deve ser observado é aquele por meio do qual toda atividade nuclear em território nacional somente será admitida para fins pacíficos e mediante aprovação do Congresso Nacional. Esta é uma questão de suma importância para a paz mundial posto que se conforme assiste, nações obstinadas a produzir energia nuclear são impedidas de fazêlo por pressão da Sociedade das Nações. O poder de destruição e de contaminação da energia atômica mal utilizada justifica tais previsões normativas. A flexibilização do monopólio federal da produção, comercialização e utilização de radioisótopos autorizadas sob regime de permissão deve ser realizada sob critérios de segurança em face da relevância do material nuclear (Mafra-Filho, 2006).

\section{CONCLUSÃO}

O presente estudo discutiu de forma resumida o início da ciência radiofarmácia no mundo e no Brasil e, desta forma norteia os primeiros passos dados no sentido de viabilizar uma ciência, que hoje é indispensável à medicina nuclear. Não obstante, ressalta a importância e os desafios atribuídos a Emenda Constitucional N. 49, que coloca o Brasil, hoje, frente a uma série de questionamento quanto à produção privada de radiofármacos, dentre eles: legislação sanitária especifica,formação de pessoal capacitado e responsabilidade civil. 


\section{ABSTRACT \\ Radiopharmacy history and implications of amendment 49}

The purpose of this paper is to describe the history of radiopharmaceutical and the implications of amendment 49 upon the radiopharmaceuticals production in Brazil.

UNITERMS: Radiopharmacy. Radiopharmaceuticals/ production/legislative aspects. Amendment 49/ implications.

\section{REFERÊNCIAS BIBLIOGRÁFICAS}

BLUMGART, H.L.; YENS, O.C. Studies on the velocity of blood flow: I. The method utilized. J. Clin. Invest. v.4, n.1, p.1-13, 1926.

BRASIL, Constituição da República Federativa do Brasil. Diário Oficial da União, Brasília, 5 out. 1988. Seção 1, p.1.

BRASIL, Emenda Constitucional no.49. Altera a redação da alínea $b$ e acrescenta alínea $e$ ao inciso XXIII do caput do art. 21 e altera a redação do inciso V do caput do art. 177 da Constituição Federal para excluir do monopólio da União a produção, a comercialização e a utilização de radioisótopos de meia-vida curta, para usos médicos, agrícolas e industriais. Diário Oficial da União, Brasília, 8 fev. 2006. Seção 1, p.1.

BRASIL, CASA CIVIL. Lei no. 8.987, Dispõe sobre o regime de concessão e permissão da prestação de serviços públicos previstos no artigo 175 da Constituição Federal e dá outras providências. Diário Oficial da União, Brasília, 13 fev 1995. Seção 1, p.1917.

BRASIL. Decreto Lei 3.365, Lei Geral de Desapropriações, dispõe sobre desapropriações por utilidade pública. Diário Oficial da União, 21 jun. 1941. Seção 1, p.14427.

EARLY, P. J. Use of diagnostic radionuclides in medicine. Health Phys., v.69, n.5, p.649-661 1995.

EARLY, J. P; LANDA, E. R. Use of therapeutic radionuclides in medicine. Health Phys., v.69, n.5, p.677-694, 1995.
MAFRA-FILHO, F.S.A. A Emenda Constitucional n. 49comentários e análise da EC 49/06. Disponível em: $<$ http:/ /www.direitonet.com.br/artigos/x/25/31/2531/>. Acesso em: 24 nov.2006.

HERTZ, S.; ROBERT, A.; EVANS, R.D. Radioactive iodine as an indicator in the study of thyroid physiology. Proc. Soc. Exptl. Biol.Med., v.38, p.510-513, 1938.

LANDA, E.R. Buried treasure to buried waste: the rise and fall of the radium industry. CMS Quarterly, v. 82, n.2, 1987. $77 \mathrm{p}$.

MELLO, C. A. B. Curso de Direito Administrativo. 11. ed. Rio de Janeiro: Malheiros, 2001. p.611.

OAK RIDGE NATIONAL LABORATORIES. Availability of radioactive isotopes. Science, v.10, p.391, 1945.

SANTOS-OLIVEIRA, R.; CARNEIRO-LEÃO, A.M.A. Radiofarmácia no Brasil após a Emenda Constitutional 49: aspectos legislativos. Rev. Veredas do Direito, v. 4, n.7, p.109-118, 2007.

SAUBERMANN, S. The curative action of radium. New York: Radium Limited, 1914. 113p.

SILVA, N.C. Histórico das biociências nucleares: evolução das biociências nucleares no Brasil - de 1942 a 2001. Alasbim Journal, v.4, n.14, p.1-5, 2002. n.p.

SIMPSON, F.E. Radium therapy. St. Louis: C.V. Mosby, 1922. p.391.

TAUSSIG, L. Carcinoma of the tongue and its treatment with radium. Radium, v.2, p.9-17, 1923.

THE INTERNATIONAL PHARMACOPOEIA. Radiopharmaceutical. 3.ed. Geneve: World Health Organization, 2004. 88p.

TEWSON, T.J; KROHN, K.A. Pet radiopharmaceuticals: state-of-the-art and future prospects. Sem. Nucl. Med., v.28, n.3, p.221-234, 1998.

WOLF, W.; TUBIS, M. Radiopharmaceuticals. J. Pharm. Sci., v.56, n.1, p.1-17, 1967.

Recebido para publicação em 07 de fevereiro de 2007 Aceito para publicação em 13 de dezembro de 2007 